Article

\title{
Liver proteome profile of growth restricted and appropriately grown newborn Wistar rats associated with maternal undernutrition
}

Polyxeni-Maria Sarli", Antigoni Manousopoulou²\#, Elias Efthymiou ${ }^{1}$, Andreas Zouridis ${ }^{1}$, Anastasios Potiris ${ }^{1}$, Panagiota Pervanidou ${ }^{3}$, Konstantinos Panoulis ${ }^{1}$, Nikolaos Vlahos ${ }^{1}$, Efthymios Deligeoroglou ${ }^{1}$, Spiros D. Garbis $^{4,5}$ and Makarios Eleftheriades ${ }^{1}$

\# Equally first authors.

\author{
${ }^{1}$ National and Kapodistrian University of Athens, 2nd Department of Obstetrics and Gynecology - \\ Aretaieion Hospital, Athens, Greece \\ 2University of Southampton, Institute for Life Sciences, Southampton, United 11 Kingdom \\ ${ }^{3}$ National and Kapodistrian University of Athens, Unit of Developmental and Behavioral Pediatrics - \\ 1st Department of Pediatrics, Athens, Greece \\ ${ }^{4}$ University of Southampton, Institute for Life Sciences, Southampton, United 11 Kingdom \\ ${ }^{5}$ Current Adress: Proteas Bioanalytics Inc., BioLabs at the Lundquist Institute, Torrance, CA, USA
}

${ }^{*}$ Corresponding authors

elinasar@med.uoa.gr ;

melefth@med.uoa.gr

Abstract: (1) Background: Fetal Growth Restriction (FGR) has been associated with 
adverse perinatal outcomes and epigenetic modifications that impact gene expression leading to permanent changes of fetal metabolic pathways and thereby influence development of disease in childhood and adult life. Both clinical and experimental studies showed that maternal nutrition during pregnancy is critical since malnutrition adversely affects fetal growth and physiology. In this study, we investigated the result of maternal food restriction on liver protein expression in Wistar male newborn pups. (2) Materials \& methods: Pups born to food restricted mothers were subdivided to FGR and non-FGR groups. Livers of control, FGR and non-FGR groups were analyzed using quantitative proteomics. (3) Results: In total 6665 proteins were profiled. Of these, 451 and 751 were differentially expressed in FGR and non-FGR vs. control respectively, whereas 229 were common between the two groups. Bioinformatics analysis of the differentially expressed proteins (DEPs) in FGR vs. control revealed: induction of the super-pathway of cholesterol biosynthesis and inhibition of thyroid hormone metabolism, fatty acid beta oxidation and apelin liver signaling pathway. In the DEPs of non-FGR vs. control groups there was inhibition of thyroid hormone metabolism, fatty acid beta oxidation and apelin liver signaling pathway as well. (4) Conclusion: This study demonstrates the impact of prenatal food restriction on the proteomic liver profile of FGR and non-FGR offspring underlying the importance of both prenatal adversities and birth weight on liver dependent postnatal disease.

Keywords: FGR; fetal programming; food restriction; metabolic disorders; liver proteomics

\section{Introduction}


Fetal Growth Restriction (FGR) refers to a fetus that has failed to achieve its biological growth potential due to pathological conditions such as maternal / fetal disease and placental dysfunction. Fetal growth impairment is associated with perinatal morbidity and mortality, a 5 to 10 -fold risk of in utero demise [14] and adverse neonatal outcomes [28]. Furthermore, according to Barker's hypothesis, an unfavorable intrauterine environment may have negative long-term effects in adult life [1]. According to the thrifty phenotype hypothesis [2], FGR impairs the growth of organs such as the liver in order to maintain homeostasis of other crucial for survival organs and systems. These metabolic adaptations, enable fetuses to survive in a malnourished intrauterine environment. However, the cost of these adaptations is permanent physiological and epigenetic phenotypical alterations that are responsible for development of disease later in life such as obesity, diabetes and cardiovascular disease.

Nutrition is one of the environmental variables with the widest range of effects on both physical growth and metabolism [3,33]. An expanding body of epidemiological evidence suggests that the nutritional environment experienced in fetal life increases the risk of chronic non-communicable diseases associated with human ageing. Maternal undernutrition constitutes a serious public health problem exhibiting large regional and within-country variations across the globe. Proper nutrition from preconception to delivery is critical for avoiding poor pregnancy and long-term outcomes for both the mother and child [51]. To date, many experimental approaches have been designed to study the impact of FGR intervening either in maternal nutrition, placental blood flow or fetal wellness. Restricting maternal food intake is advantageous since it leads to an altered intrauterine nutritional milieu and growth impairment avoiding surgical intervention. Moreover, this type of animal model is closer to pregnancy malnutrition effects observed in humans $[35,45]$. Although a large number of animal models of FGR have investigated the impact of intrauterine environment on fetal epigenetic programming, there is little knowledge about the effects of 
maternal undernutrition on liver growth and physiology of appropriately grown (non-FGR) offspring of undernurished pregnancies.

Liver plays a major role in nutrients' absorption and metabolism. During pregnancy, fetal growth restriction not only affects adversely liver's growth but also its physiological function [43]. Metabolic disorders namely, reduced oxidative phosphorylation, impaired mitochondrial function, antioxidant capacity and altered nutrient metabolism are commonly found in FGR livers [42,34,22]. It has been demonstrated that liver of FGR offspring seems to have an abnormally increased rate of glyconeogenesis contributing to insulin resistance and hyperglycemia [24,39]. Nevertheless, the exact mechanisms which are responsible for alterations in development, growth and liver function leading to hepatic diseases are not adequately described.

Our aim was to investigate the impact of maternal food deprivation on liver proteomic profile in three groups of newborn male Wistar rats: a) offspring of mothers that received standard laboratory diet (control group) , b) offspring of food restricted mothers with low birth weight (FGR group) and c) appropriately grown offspring of food restricted mothers (non - FGR group).

Furthermore, the aim of this study was to examine whether prenatal food restriction during late gestation affects offspring liver proteome irrespective of birth weight and propose possible underlying pathophysiological mechanisms of liver fetal programming

\section{Results}




\section{Experimental model}

There was no statistical difference in post-delivery maternal bodyweight in both diet groups (control: $265 \pm 25 \mathrm{gr}$, starved $270 \pm 20 \mathrm{gr} p=0.769$ ). Control group mothers (ad libitum food access) gave birth to control pups with mean body weight of $6.419 \mathrm{gr}$ (SD: 0.436). The mean birthweight of the food restricted group was $5.423 \mathrm{gr}$, significantly different compared to controls $(5.423 \pm 0.610 \mathrm{gr}$ vs. $6.419 \pm$ $0,436 \mathrm{gr} ; \mathrm{p}<0,001)$. Male neonates were heavier compared to females in the control group $(6.659 \mathrm{~g}$ vs $6.2 \mathrm{~g}, \mathrm{p}<0.001)$ but there was no statistically significant difference between them in the starved group $(p=0.666)$.

Newborn pups delivered by starved mothers, were further divided to Fetal Growth Restricted (FGR) group when birthweight was < - 2SDs of the mean BW of the control offspring and non-FGR group when birthweight was > - 2SDs of the mean BW of the control. The cut-off between FGR and non-FGR neonates was set at 5.547gr according to the aforementioned definition. Furthermore, there was statistically significant birthweight difference between FGR $(4.796 \mathrm{gr} \pm 0.479 \mathrm{gr})$ and non-FGR (5.914gr $\pm 0,479$ gr) groups $(p<0,001)$.

Although liver weight of the non-FGR group was statistically significant higher compared to FGR pups $(0.211 \pm 0.047$ vs. $0.280 \pm 0.073, p<0.0014)$, there was no difference in the liver weight to body weight ratio between groups $(0.04274 \pm 0.00743$ vs. $0.04721 \pm 0.01220, p=0.10337)($ Table 1$)$

Table 1. Mean values for all experimental outcomes and comparisons between study groups 


\begin{tabular}{|c|c|c|c|c|}
\hline & Group & Mean & SD & p-value \\
\hline $\begin{array}{r}\text { Length of } \\
\text { gestation (days) }\end{array}$ & $\begin{array}{r}\text { Starved } \\
\text { control }\end{array}$ & $\begin{array}{l}21.22 \\
20.73\end{array}$ & $\begin{array}{l}0.47 \\
0.06\end{array}$ & 0.081 \\
\hline Litter size (pups) & $\begin{array}{r}\text { Starved } \\
\text { control }\end{array}$ & $\begin{array}{l}10.83 \\
11.50\end{array}$ & $\begin{array}{l}1.72 \\
1.29 \\
\end{array}$ & 0.530 \\
\hline $\begin{array}{r}\text { Post delivery } \\
\text { maternal } \\
\text { weight(g) }\end{array}$ & $\begin{array}{l}\text { Starved } \\
\text { Control }\end{array}$ & $\begin{array}{l}268.83 \\
264.50\end{array}$ & $\begin{array}{l}26.75 \\
10.47\end{array}$ & 0.304 \\
\hline Birth weight (g) & $\begin{array}{r}\text { Starved } \\
\text { control }\end{array}$ & $\begin{array}{l}5.423 \\
6.419 \\
\end{array}$ & $\begin{array}{l}0.610 \\
0.436 \\
\end{array}$ & $<0.001$ \\
\hline \multirow{2}{*}{ Liver weight (g) } & $\begin{array}{l}\text { Starved } \\
\text { Control }\end{array}$ & $\begin{array}{l}0.245 \\
0.266\end{array}$ & $\begin{array}{l}0.070 \\
0.057\end{array}$ & 0.117 \\
\hline & $\begin{array}{r}\text { Fgr } \\
\text { non-Fgr }\end{array}$ & $\begin{array}{l}0.211 \\
0.280\end{array}$ & $\begin{array}{l}0.047 \\
0.073\end{array}$ & \multirow[t]{2}{*}{$<0.001$} \\
\hline \multirow{2}{*}{$\begin{array}{r}\text { Liver to body } \\
\text { weight }(\mathrm{g})\end{array}$} & $\begin{array}{l}\text { Starved } \\
\text { Control }\end{array}$ & $\begin{array}{l}0.04498 \\
0.41753\end{array}$ & $\begin{array}{l}0.01026 \\
0.00946\end{array}$ & \\
\hline & $\begin{array}{r}\text { Fgr } \\
\text { non-Fgr }\end{array}$ & $\begin{array}{l}0.04274 \\
0.04721\end{array}$ & $\begin{array}{l}0.00743 \\
0.01220\end{array}$ & 0.103 \\
\hline \multirow{2}{*}{ Brain weight $(\mathrm{g})$} & $\begin{array}{l}\text { Starved } \\
\text { Control }\end{array}$ & $\begin{array}{l}0.150 \\
0.180\end{array}$ & $\begin{array}{l}0.045 \\
0.044\end{array}$ & $<0.001$ \\
\hline & $\begin{array}{r}\text { Fgr } \\
\text { non-Fgr }\end{array}$ & $\begin{array}{l}0.151 \\
0.148 \\
\end{array}$ & $\begin{array}{l}0.058 \\
0.043\end{array}$ & 0.783 \\
\hline \multirow{2}{*}{$\begin{array}{r}\text { Brain to body } \\
\text { weight (g) }\end{array}$} & $\begin{array}{l}\text { Starved } \\
\text { Control }\end{array}$ & $\begin{array}{l}0.02826 \\
0.02806\end{array}$ & $\begin{array}{l}0.00968 \\
0.00598\end{array}$ & 0.905 \\
\hline & $\begin{array}{r}\text { Fgr } \\
\text { non-Fgr }\end{array}$ & $\begin{array}{l}0.03157 \\
0.02496\end{array}$ & $\begin{array}{l}0.01093 \\
0.00698\end{array}$ & 0.009 \\
\hline
\end{tabular}




\section{Proteomic Analysis}

Proteomic analysis of male offspring livers ended up in the profiling of 6,665 proteins (peptide level $q<0.05$ ) (Supplementary Table 1). Among the quantified proteins, 451 proteins were differentially expressed in FGR vs. control (Supplementary Table 2) and 782 in non-FGR vs. control group (Supplementary Table 3). Of these, 76 were commonly up-regulated and 153 commonly downregulated in both FGR and non-FGR compared to control (Supplementary Table $3)$.

Principal component analysis (PCA) of all quantified proteins showed a distinct proteomic liver profile of FGR compared to non-FGR rats (figure 1). Bioinformatics analysis of differentially expressed proteins (DEPs) in FGR compared to control groups using Ingenuity Pathway Analysis (IPA) showed: a. induction of the super pathway of cholesterol biosynthesis $(z=2.2 ; p=1.5 e-4)$ (figure 2), and b. inhibition of thyroid hormone metabolism (figure 3) ( $z=-2.0$; $p=4.6 e-3)$, fatty acid beta oxidation $(z=-2.0 ; p=2.7 e-3)$ (figure 4) and apelin liver signaling pathway (figure 5) $(z=-2.2 ; p=8.5 e-5)$. Enrichment analysis of the DEPs in non-FGR vs. control groups using IPA showed: a. induction of immune cell adhesion $(z=2.9 ; p=1.1 \mathrm{e}-7)$ and $b$. inhibition of thyroid hormone metabolism $(z=-2.0 ; p=2.5 e-2)$, fatty acid beta oxidation $(z=-2.0 ; p=1.6 e-2)$ and apelin liver signaling pathway $(z=-2.0 ; p=6.7 e-3)$ (figure 6$)$. 


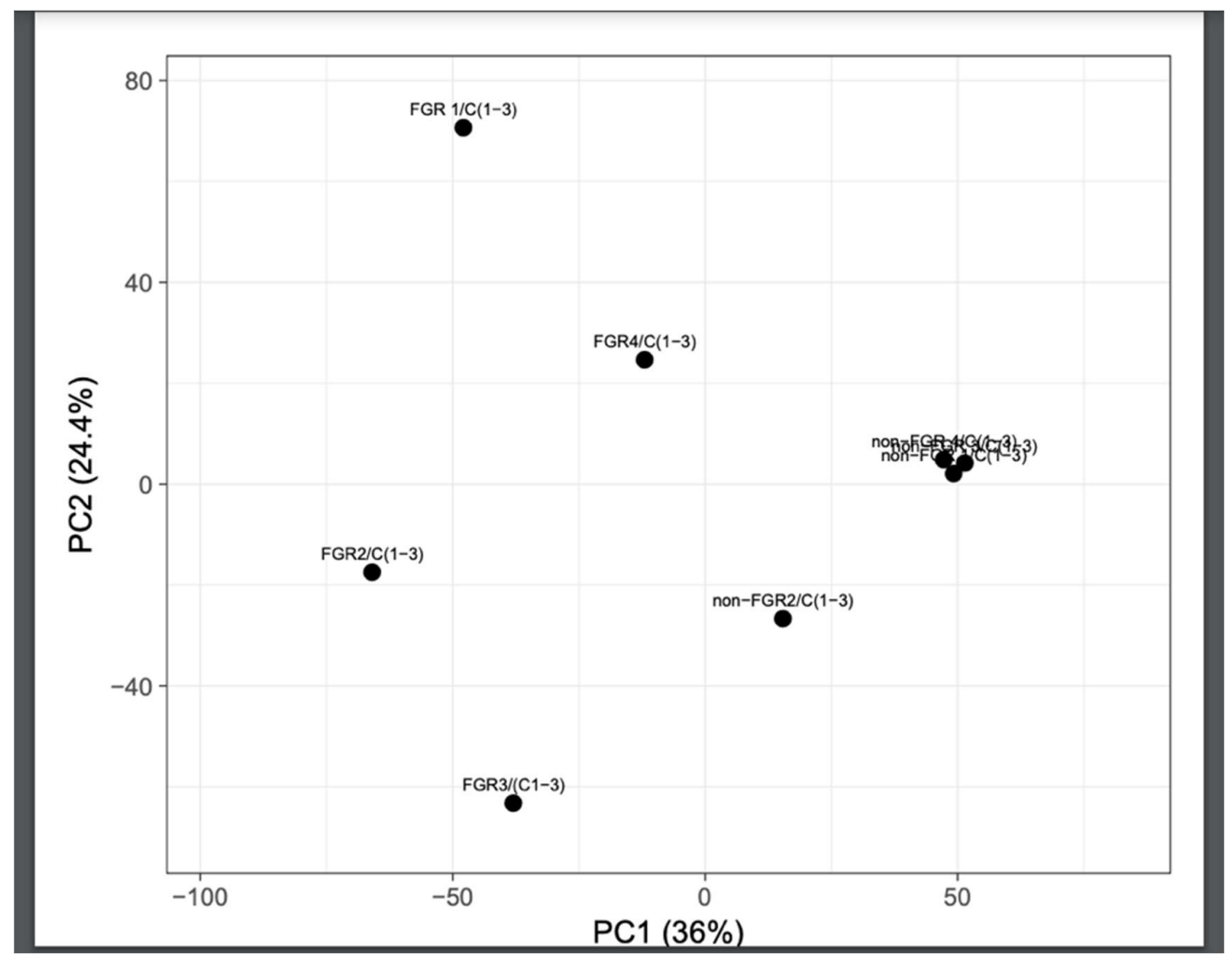

Figure 1. Principal component analysis (PCA) of all quantified proteins revealed that liver of fetal growth restrictes pups had a heterogeneous proteomic profile compared to non-FGR ones. 


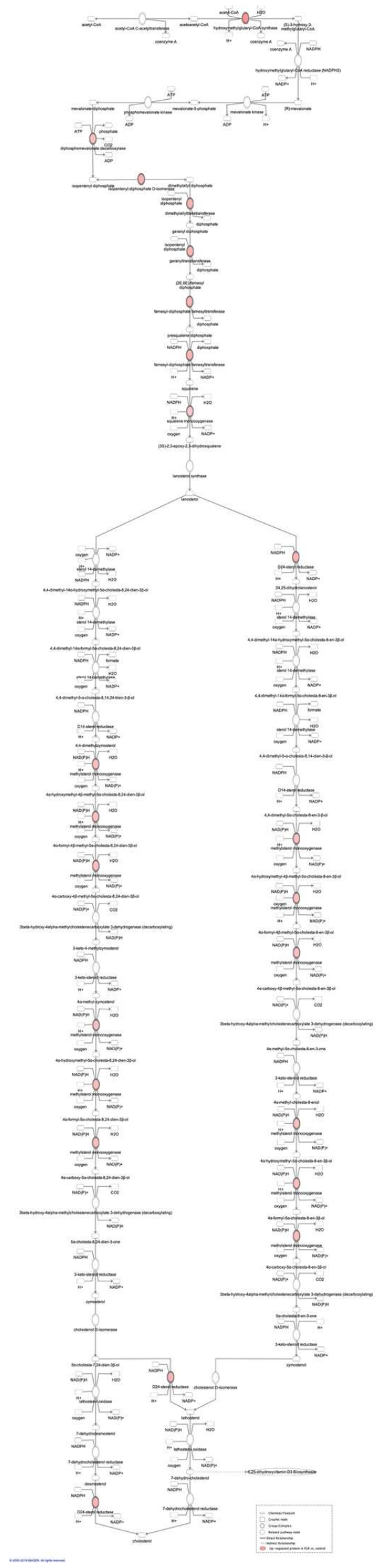

Figure 2. Ingenuity Pathway Analysis of DEPs between FGR vs. Control group. Induction of the super pathway of cholesterol biosynthesis.

$z=2.2 \quad p=1.5 e-4$ 
Figure 3. Ingenuity Pathway Analysis of DEPs between FGR vs. Control group. Inhibition of thyroid hormone metabolism $z=-2.0 p=4.6 e-3$

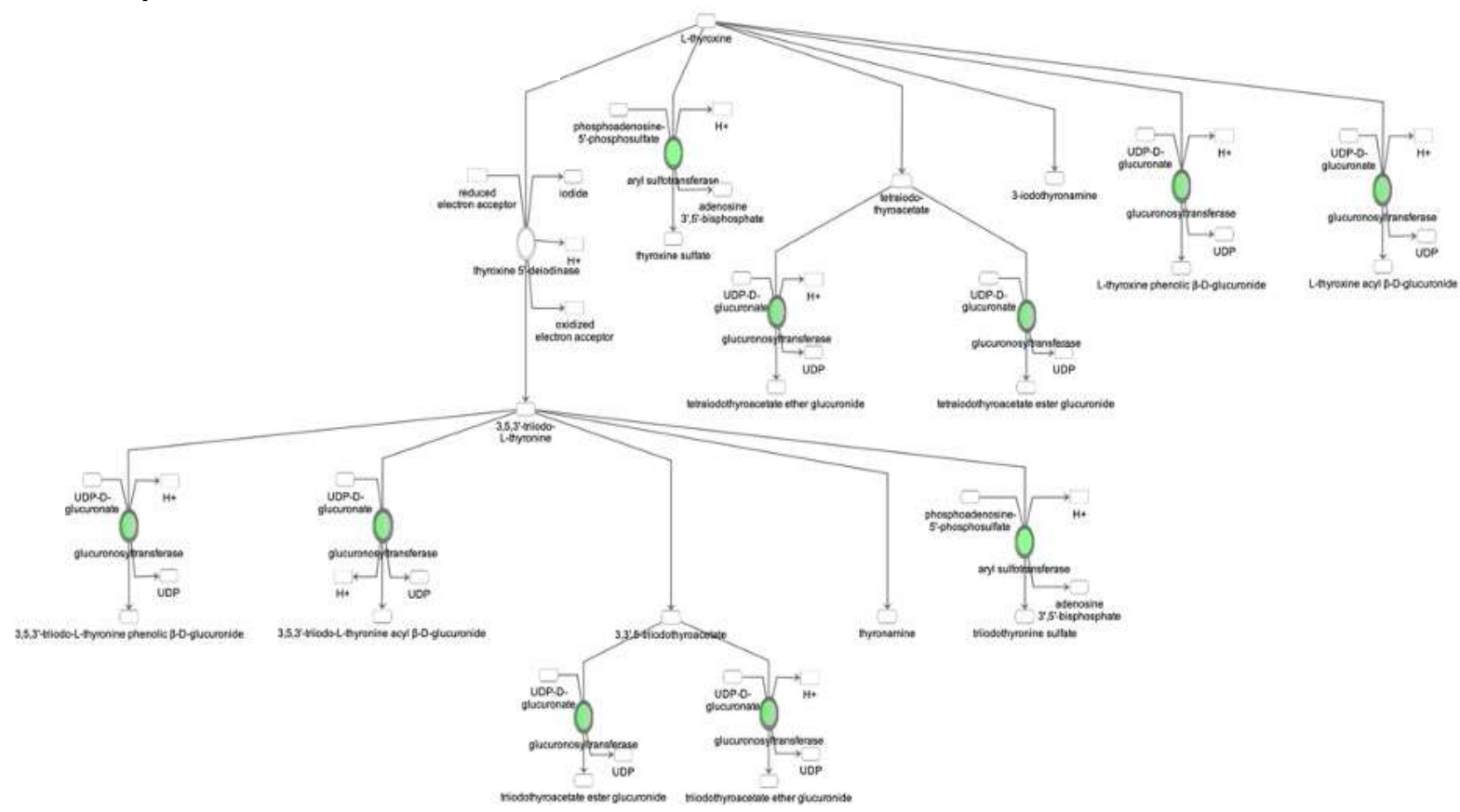

Figure 4. Ingenuity Pathway Analysis of DEPs between FGR vs. Control group. Inhibition of fatty acid beta oxidation $z=-2.0 \quad p=2.7 e-3$

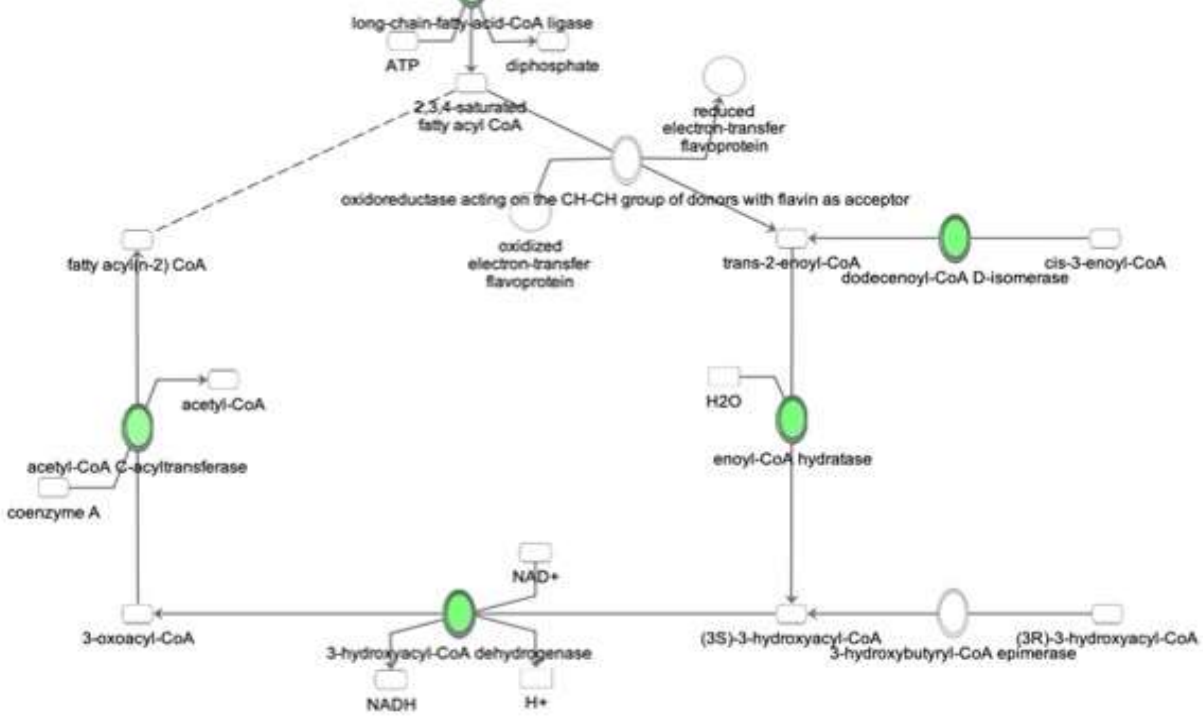


Apelin inhibits liver regeneration while promoting hepatic fibrosis upon injury. It also has anti-insulin resistance properties,

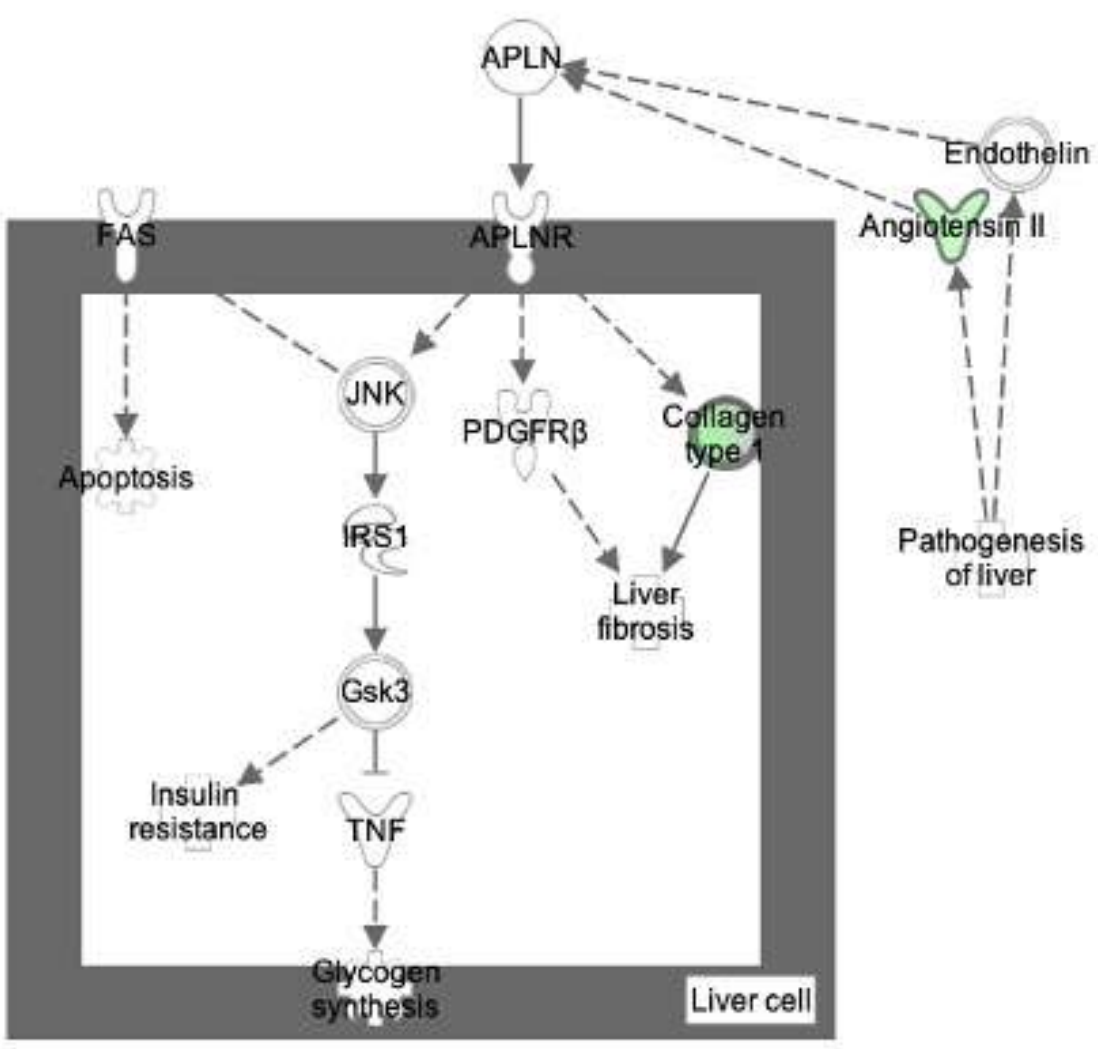

Figure 5. Ingenuity Pathway Analysis of DEPs between FGR vs. Control group. Inhibition of apelin liver signaling pathway

$z=-2.2 p=8.5 e-5$ 


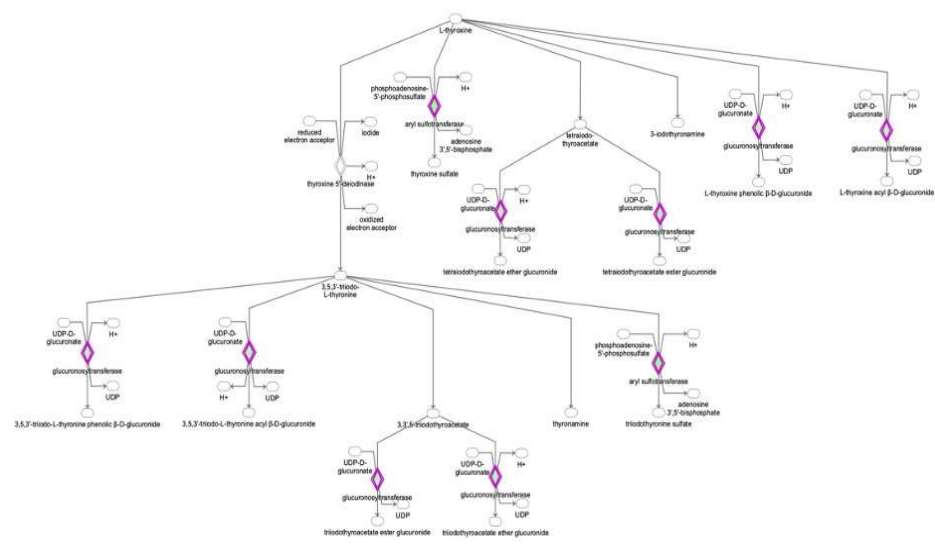

thyroid hormone metabolism

fatty acid beta oxidation
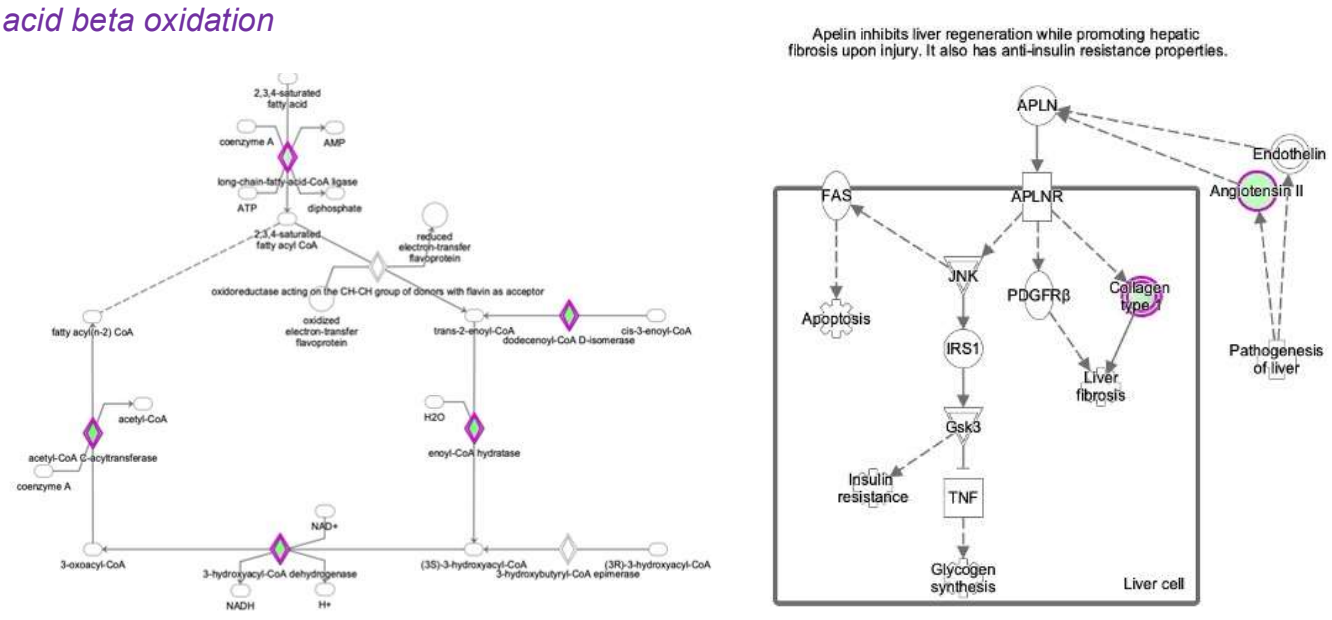

Figure 6. Ingenuity Pathway Analysis of differentially expressed proteins in non-FGR compared to control group showed inhibition of thyroid hormone metabolism $(z=-2.0 \quad p=2.5 e-2)$, fatty acid beta oxidation $(z=-2.0 p=1.6 e-2)$ and apelin liver signaling pathway $(z=-2.0 \quad p=6.7 e-3)$

\section{Discussion}

Numerous studies have shown the impact of adverse early-life environment on disease during infancy, childhood and adult life [5]. FGR is associated with significant perinatal and subsequent long-term morbidity and mortality. FGR neonates and infants demonstrate a variety of complications involving multiple organs and systems such as pulmonary, gastrointestinal, immune and central nervous system. Regarding the endocrine system, FGR is associated with altered glucose metabolism, transiently low thyroxin levels and cortisol deficiency. 
Furthermore, FGR programs both childhood and adult disease, associated with increased risk of obesity, insulin resistance and cardiovascular disease.

Using a well-defined FGR rat model, this study shows that maternal food restriction plays a crucial role, impairing liver intrauterine growth and altering its proteomic expression. In our study liver weight was reduced in proportion to body weight in FGR compared to non-FGR pups. On the contrary, brain weight did not differ significantly between the abovementioned two groups (Table 1) indicating a late-onset FGR model resembling to the commonest FGR phenotype in human population [23]. This study aimed to a better understanding of the proteomic mechanisms of liver developmental dysfunction induced by prenatal food restriction investigating possible differentiations in liver proteomic expression in both growth restricted (FGR) and appropriately grown (non-FGR) offspring born to starved mothers.

Bioinformatics analysis of DEPs in the FGR group vs. control showed induction of cholesterol biosynthesis. Regarding cholesterol biosynthesis, metabolomic studies have shown that FGR fetuses have higher concentrations of cholesterol such as VLDL and LDL, lipoproteins and triglycerides [29]. Lipids are vital molecules for life, providing energy for metabolic processes. Furthermore, cholesterol is a key element for brain neurodevelopment and a precursor of many hormones like sex steroids $[6,20]$. Fetal liver is the main source of circulating lipoproteins, as in adults. Alterations of VLDL concentrations, which is mostly synthesized in fetal liver, implies an altered hepatic synthesis of lipoproteins caused by FGR. Remarkably, the lipid profile of FGR fetuses resembles to adults presenting with atherosclerosis and dyslipidemia [48].

The apelin signaling pathway, thyroid metabolism and fatty acid beta oxidation were inbibited in both FGR and non-FGR neonate rats, indicating these might be a result of maternal undernutrion regardless the fetus' growth.

Apelin is a regulatory peptide and in conjunction with its receptor, are both expressed in a wide range of tissues such as central nervous system, heart and 
liver. Apelin is also produced by adipocytes and latest studies proposed its crucial role in energy metabolism and enhancement of insulin sensitivity [27]. Our study in accordance with previous ones, have shown inhibition of apelin signaling and reduced plasma concentrations as a potential response to undernutrition [7]. Recent studies have highlighted the paramount importance of apelin and its receptor, since they have been proposed as a valuable new treatment target in type 2 diabetes [10,30].

Our study showed that in both FGR and non-FGR offspring of calorie restricted mothers, liver thyroid hormones' metabolism is inhibited. Thyroid hormones play a key role to thermoregulation, specifically in norepinephrine (NE) controlled thermogenesis [44]. Brown adipose tissue thermogenic activity which is triggered by NE is under triiodothyronine $\left(T_{3}\right)$ control [32]. Low T3 plasma levels are associated with impaired thermogenesis and predisposition to dietinduced obesity in neonatal and adult life despite later normalization of $\mathrm{T}_{3}$ plasma concentrations $[9,37]$. Hypothermia and transiently low thyroxine levels are common neonatal complications of FGR however no information is available in appropriately grown neonates born to undernourished mothers [36].

Our model suggests inhibition of fatty acid metabolism not only in FGR liver but in non-FGR liver as well. Liver is the central organ of fatty acid metabolism. Both obesity and insulin resistance are close related with disrupted fatty acid metabolism [40]. Inhibition of this metabolic process leads to non-alcoholic fatty liver, liver steatosis and subsequent insulin resistance deterioration. In a previous study of our team where NEFA (Non Esterified Fatty Acids) concentrations were compared between FGR and non-FGR rats at one year of age there was no statistical difference between groups. It seems that food restriction produces the same adipose tissue response in both the FGR and non-FGR groups, suggesting that it is the adverse prenatal event that determines certain metabolic profiles rather than birthweight [12]. 


\section{Materials and Methods}

\section{Animal model}

Ten $(n=10)$ timed pregnant Wistar rats, on their $12^{\text {th }}$ day of gestation (Janvier Labs - Rodent research models \& associated services, France), were hosted individually in $36 \times 20 \times 14 \mathrm{~cm}$ breeding boxes at the Laboratory of Experimental Surgery of the Second Department of General Surgery at Aretaieion Hospital, National and Kapodistrian University of Athens, Athens, Greece. Animals were housed under standard conditions (temperature between $22^{\circ}$ and $23^{\circ} \mathrm{C}$, humidity $55-65 \%$ and 12 -hour light/dark cycles). All animals were fed with standard formula diet containing $18.5 \%$ protein (Mucedola S.r.l., Settimo Milanese, Italy) with ad libitum access to food and water as well, until day 14. Following randomization, pregnant dams were assigned to starved group $(n=6$, diet restricted by $50 \%$ ) and control group ( $n=4$ ad libitum access to food). Both groups had free access to fresh water. Control group's food intake was measured on a daily basis. During the experimental period (from day 15th onwards), rats of the starved group, were given half the amount of food that was on average consumed by the control group, based on measurements taken place the day before. Food restriction of the starved group lasted from $15^{\text {th }}$ gestational day to delivery. All rats delivered spontaneously on the $21^{\text {st }}$ gestational day and neonates were immediately weighted (figure 7).

Figure 7. Experimental design of the study. 


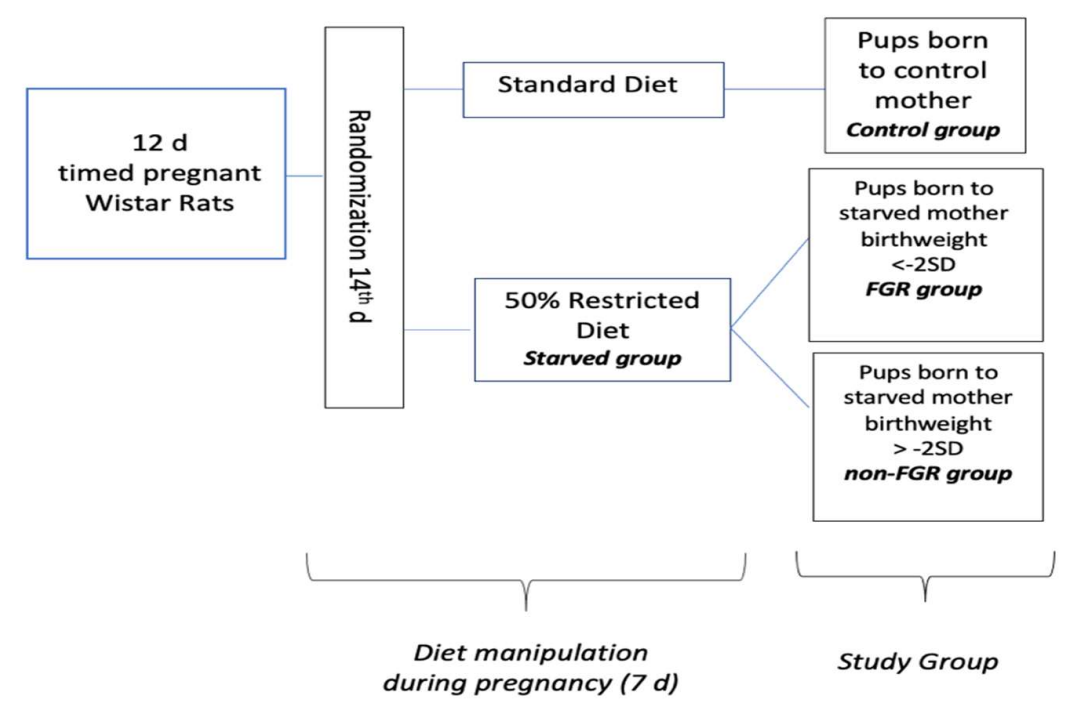

Starved group's offspring were categorized according to their birth weight as FGR (birth weight $<$ mean birth weight of control group's offspring $-2 \times$ Standard Deviation) and non FGR (birth weight > mean birth weight of control group's offspring $-2 \times$ Standard Deviation) as previously described $[11,38,50,52]$. Immediately after delivery, offspring were separated from their mothers and weighted. Neonates were anesthetized using inhaled sevoflurane, and euthanized. Liver tissues were rapidly removed. The time interval between rat's sacrifice and specimens' storage at $-80^{\circ} \mathrm{C}$ did not exceed 15 minutes.

All liver tissues were cleaned from blood with PBS (phosphate buffered saline). Specimens were stored at $-80^{\circ} \mathrm{C}$ and sent packed in dry ice to the Centre for Proteomic Research, Institute for Life Sciences, University Southampton for proteomic analysis.

Growth characteristics of mothers, gestation duration, litter size, birth weight of the pups and organ weight were compared using the independent-samples t-test (IBM SPSS Statistics 22.0). Statistical significance was considered at $p<0.05$.

All experimental procedures were approved by the Greek Directorate of Veterinary Services (1211/19-03-2018) and the Ethical Committee of Aretaieion Hospital 
(011/21-11-2017) and were in accordance with both European Union and National legislation.

\section{Quantitative proteomics:}

Each liver tissue was dissolved in $200 \mu \mathrm{L}$ of $0.5 \mathrm{M}$ triethylammonium bicarbonate, $0.05 \%$ sodium dodecyl sulfate and homogenised using the FastPrep ${ }^{\circledR}-24$ Instrument (MP Biomedicals, Santa Ana, CA, USA). Lysates were subjected to pulsed probe sonication (Misonix, Farmingdale, NY, USA) and centrifuged $\left(16,000 \mathrm{~g}, 10 \mathrm{~min}, 4^{\circ} \mathrm{C}\right)$. The supernatant had been measured for its protein content using the Direct Detect ${ }^{\mathrm{TM}}$ system (Merck Millipore, Darmstadt, Germany). From each lysate, $100 \mu \mathrm{g}$ of protein subjected to reduction, alkylation, trypsin proteolysis and 11-plex TMT labelling according to manufacturer's instructions.

The resulting TMT peptides were initially fractionated with alkaline $C_{4}$ reversed phase (RP) liquid chromatography. Each peptide fraction further separated with on-line nano-capillary $\mathrm{C}_{18}$ reverse phase liquid chromatography under acidic conditions, subjected to nanospary ionization and measured with ultra-high resolution mass spectrometry using the hybrid ion-trap / FT-Orbitrap Elite platform.

The unprocessed raw data files were submitted to Proteome Discoverer 1.4 for target decoy searching with SequestHT against the TREMBL Uniprot database for rattus norvegicus (release date: January 2018). Reporter ion ratios derived from unique peptides only were used for the relative quantitation of each respective protein. Quantification ratios were median-normalized and $\log _{2}$ transformed. The threshold of percent co-isolation excluding peptides from quantification was set at 50. A one-sample T-Test was performed to identify proteins that were differentially expressed in the tissue from FGR and non-FGR compared to control rats. The twostage step-up method of Benjamini, Krieger and Yekutieli was used for multiple hypothesis correction. A q-value $\leq 0.05$ was considered significant. Proteomics 
data have been deposited to the ProteomeXchange Consortium via the PRIDE partner repository.

\section{Conclusions}

According to fetal programming theory, fetal malnutrition induces adaptive processes that permanently change growth, physiology and metabolism of the offspring. Maternal undernutrition alters the proteomic profile of the neonatal liver which is a key organ of many metabolic processes supporting homeostasis. In our study, FGR (representing a model of human neonates with growth restriction) and non-FGR pups (representing a model of human infants having experienced adverse intrauterine conditions but born with normal body weight) have developed both common and different metabolic phenotypes. Thus suggesting that both intrauterine adversities and birthweight determine the metabolic profiles of the offspring. This study contributes to a better understanding of the proteomic mechanisms of liver developmental dysfunction induced by prenatal food restriction and helps to explain the intrauterine origin of adult metabolic disease.

Author contributions: Conceptualization, Makarios Eleftheriades; Formal analysis, Polyxeni - Maria Sarli, Antigoni Manousopoulou, Anastasios Potiris, Andreas Zouridis and Elias Efthymiou; Funding acquisition, Polyxeni- Maria Sarli and Makarios Eleftheriades; Investigation, Polyxeni-Maria Sarli, Antigoni Manousopoulou, Anastasios Potiris, Andreas Zouridis and Makarios Eleftheriades; Methodology, Polyxeni-Maria Sarli, Antigoni Manousopoulou, Spiros Garbis and Makarios Eleftheriades; Project administration, Makarios Eleftheriades; Resources, Makarios Eleftheriades and Spiros Garbis; Supervision, Konstantinos Panoulis, Panagiota Pervanidou, Nikolaos Vlahos, Spiros Garbis and Makarios Eleftheriades; Visualization, Polyxeni-Maria Sarli and Antigoni Manousopoulou; Writing -original draft, Polyxeni-Maria Sarli and Antigoni Manousopoulou; Writing 
- review \& amp; editing, Antigoni Manousopoulou, Konstantinos Panoulis, Efthymios Deligeoroglou, Nikolaos Vlahos Panagiota Pervanidou, Spiros Garbis and Makarios Eleftheriades.

Funding: This research project was supported in part by Procter \& Gamble Hellas “George Papanicolaou 2018 - 2020" research grant.

Institutional Review Board Statement: All animal procedures were approved by the Directorate of Veterinary Services (protocol number 1211/19-03-2018) and the Ethical Committee of Aretaieion Hospital (protocol number 011/21-11-2017) and were in accordance with both EU and National legislation.

Informed Consent Statement: Not applicable

Data Availability Statement: The data presented in this study are available within the article. All proteomics data are uploaded at the ProteomeXchange Consortium via the PRIDE partner repository (dataset identifier PXD011407)

Conflicts of Interest: Spiros D. Garbis, PhD is Founder, President and CEO of Proteas Bioanalytics Inc., BioLabs at the Lundquist Institute, 1124 West Carson Street, MRL Building, 3rd Floor, Torrance, CA 90502.

The authors declare that this study received funding from Procter \& Gamble Hellas. The funder was not involved in the study design, collection, analysis, interpretation of data, the writing of this article or the decision to submit it for publication.

Appendix A. Supplementary tables. 


\section{References}

1. Barker, D. J., Hales, C. N., Fall, C. H., Osmond, C., Phipps, K., \& Clark, P. M. (1993). Type 2 (non-insulin-dependent) diabetes mellitus, hypertension and hyperlipidaemia (syndrome X): Relation to reduced fetal growth. Diabetologia, 36(1), 62-67. https://doi.org/10.1007/BF00399095

2. Barker, D. J., \& Osmond, C. (1986). Infant mortality, childhood nutrition, and ischaemic heart disease in England and Wales. Lancet (London, England), 1(8489), 1077-1081. https://doi.org/10.1016/s0140-6736(86)91340-1

3. Bouroutzoglou, M., Malamitsi-Puchner, A., Boutsikou, M., Marmarinos, A., Baka, S., Boutsikou, T., Hassiakos, D., Gourgiotis, D., \& Briana, D. D. (2014). Biochemical markers of bone resorption are present in human milk: Implications for maternal and neonatal bone metabolism. Acta Paediatrica, 103(12), 1264-1269.

https://doi.org/10.1111/apa.12771

4. Boutsikou, T., Mastorakos, G., Kyriakakou, M., Margeli, A., Hassiakos, D., Papassotiriou, I., Kanaka-Gantenbein, C., \& Malamitsi-Puchner, A. (2010). Circulating levels of inflammatory markers in intrauterine growth restriction. Mediators of Inflammation, 2010, 790605. https://doi.org/10.1155/2010/790605

5. Breier, B. H., Vickers, M. H., Ikenasio, B. A., Chan, K. Y., \& Wong, W. P. (2001). Fetal programming of appetite and obesity. Molecular and Cellular Endocrinology, 185(1-2), 73-79. https://doi.org/10.1016/s0303-7207(01)00634-7

6. Carr, B. R., \& Simpson, E. R. (1982). Cholesterol synthesis in human fetal tissues. The Journal of Clinical Endocrinology and Metabolism, 55(3), 447-452. https://doi.org/10.1210/jcem-55-3-447

7. Chaves-Almagro, C., Castan-Laurell, I., Dray, C., Knauf, C., Valet, P., \& Masri, B. (2015). Apelin receptors: From signaling to antidiabetic strategy. European Journal of Pharmacology, 763(Pt B), 149-159. https://doi.org/10.1016/j.ejphar.2015.05.017

8. Chiang, J. Y. L. (2004). Regulation of bile acid synthesis: Pathways, nuclear receptors, and mechanisms. Journal of Hepatology, 40(3), 539-551.

https://doi.org/10.1016/i.jhep.2003.11.006 
9. de Jesus, L. A., Carvalho, S. D., Ribeiro, M. O., Schneider, M., Kim, S.-W., Harney, J. W., Larsen, P. R., \& Bianco, A. C. (2001). The type 2 iodothyronine deiodinase is essential for adaptive thermogenesis in brown adipose tissue. Journal of Clinical Investigation, 108(9), 1379-1385. https://doi.org/10.1172/JCl200113803

10. Dray, C., Knauf, C., Daviaud, D., Waget, A., Boucher, J., Buléon, M., Cani, P. D., Attané, C., Guigné, C., Carpéné, C., Burcelin, R., Castan-Laurell, I., \& Valet, P. (2008). Apelin stimulates glucose utilization in normal and obese insulin-resistant mice. Cell Metabolism, 8(5), 437-445. https://doi.org/10.1016/j.cmet.2008.10.003

11. Eleftheriades, M., Pervanidou, P., Vafaei, H., Vaggos, G., Dontas, I., Skenderi, K., Sebire, N. J., \& Nicolaides, K. (2014). Metabolic profiles of adult Wistar rats in relation to prenatal and postnatal nutritional manipulation: The role of birthweight. Hormones, 13(2), 268-279. https://doi.org/10.1007/BF03401341

12. Eleftheriades, M., Vafaei, H., Dontas, I., Vaggos, G., Marinou, K., Pervanidou, P., Sebire, N. J., Chrousos, G. P., \& Nicolaides, K. H. (2016). Assessment of body composition in Wistar rat offspring by DXA in relation to prenatal and postnatal nutritional manipulation. Pediatric Research, 80(2), 319-325. https://doi.org/10.1038/pr.2016.61

13. Ferenc, K., Pietrzak, P., Wierzbicka, M., Matyba, P., Grzesiuk, E., Gajewski, Z., \& Zabielski, R. (2018). Alterations in the liver of intrauterine growth retarded piglets may predispose to development of insulin resistance and obesity in later life. Journal of Physiology and Pharmacology: An Official Journal of the Polish Physiological Society, 69(2). https://doi.org/10.26402/jpp.2018.2.06

14. Gardosi, J., Madurasinghe, V., Williams, M., Malik, A., \& Francis, A. (2013). Maternal and fetal risk factors for stillbirth: Population based study. BMJ (Clinical Research Ed.), 346, f108. https://doi.org/10.1136/bmj.f108

15. Guéant, J.-L., Elakoum, R., Ziegler, O., Coelho, D., Feigerlova, E., Daval, J.-L., \& Guéant-Rodriguez, R.-M. (2014). Nutritional models of foetal programming and nutrigenomic and epigenomic dysregulations of fatty acid metabolism in the liver and heart. Pflügers Archiv - European Journal of Physiology, 466(5), 833-850.

https://doi.org/10.1007/s00424-013-1339-4 
16. Hossain, M. A., Islam, M. N., Shahidullah, M., \& Akhter, H. (2006). Serum triglyceride level in IUGR babies and its comparison with preterm AGA and term normal babies. Mymensingh Medical Journal: MMJ, 15(2), 180-182.

https://doi.org/10.3329/mmj.v15i2.40

17. Howie, G. J., Sloboda, D. M., \& Vickers, M. H. (2012). Maternal undernutrition during critical windows of development results in differential and sex-specific effects on postnatal adiposity and related metabolic profiles in adult rat offspring. The British Journal of Nutrition, 108(2), 298-307. https://doi.org/10.1017/S000711451100554X

18. Jensen, M. D., Haymond, M. W., Rizza, R. A., Cryer, P. E., \& Miles, J. M. (1989). Influence of body fat distribution on free fatty acid metabolism in obesity. Journal of Clinical Investigation, 83(4), 1168-1173. https://doi.org/10.1172/JCl113997

19. Jobgen, W. S., Fried, S. K., Fu, W. J., Meininger, C. J., \& Wu, G. (2006). Regulatory role for the arginine-nitric oxide pathway in metabolism of energy substrates. The Journal of Nutritional Biochemistry, 17(9), 571-588.

https://doi.org/10.1016/j.jnutbio.2005.12.001

20. Jones, J. N., Gercel-Taylor, C., \& Taylor, D. D. (1999). Altered cord serum lipid levels associated with small for gestational age infants. Obstetrics and Gynecology, 93(4), 527-531. https://doi.org/10.1016/s0029-7844(98)00489-x

21. Kiec-Klimczak, M., Malczewska-Malec, M., Razny, U., Zdzienicka, A., Gruca, A., Goralska, J., Pach, D., Gilis-Januszewska, A., Dembinska-Kiec, A., \& HubalewskaDydejczyk, A. (2016). Assessment of incretins in oral glucose and lipid tolerance tests may be indicative in the diagnosis of metabolic syndrome aggravation. Journal of Physiology and Pharmacology: An Official Journal of the Polish Physiological Society, 67(2), 217-226.

22. Kloesz, J. L., Serdikoff, C. M., Maclennan, N. K., Adibi, S. A., \& Lane, R. H. (2001). Uteroplacental insufficiency alters liver and skeletal muscle branched-chain amino acid metabolism in intrauterine growth-restricted fetal rats. Pediatric Research, 50(5), 604610. https://doi.org/10.1203/00006450-200111000-00012 
23. Lees, C. C., Stampalija, T., Baschat, A. A., Silva Costa, F., Ferrazzi, E., Figueras, F., Hecher, K., Kingdom, J., Poon, L. C., Salomon, L. J., \& Unterscheider, J. (2020). ISUOG Practice Guidelines: Diagnosis and management of small-for-gestational-age fetus and fetal growth restriction. Ultrasound in Obstetrics \& Gynecology, 56(2), 298312. https://doi.org/10.1002/uog.22134

24. Limesand, S. W., Jensen, J., Hutton, J. C., \& Hay, W. W. (2005). Diminished betacell replication contributes to reduced beta-cell mass in fetal sheep with intrauterine growth restriction. American Journal of Physiology. Regulatory, Integrative and Comparative Physiology, 288(5), R1297-1305. https://doi.org/10.1152/ajpregu.00494.2004

25. Liu, C., Lin, G., Wang, X., Wang, T., Wu, G., Li, D., \& Wang, J. (2013). Intrauterine growth restriction alters the hepatic proteome in fetal pigs. The Journal of Nutritional Biochemistry, 24(6), 954-959. https://doi.org/10.1016/j.jnutbio.2012.06.016

26. Malamitsi-Puchner, A., Briana, D. D., Boutsikou, M., Kouskouni, E., Hassiakos, D., \& Gourgiotis, D. (2007). Perinatal circulating visfatin levels in intrauterine growth restriction. Pediatrics, 119(6), e1314-1318. https://doi.org/10.1542/peds.2006-2589

27. Mayeur, S., Wattez, J.-S., Lukaszewski, M.-A., Lecoutre, S., Butruille, L., Drougard, A., Eberlé, D., Bastide, B., Laborie, C., Storme, L., Knauf, C., Vieau, D., Breton, C., \& Lesage, J. (2016). Apelin Controls Fetal and Neonatal Glucose Homeostasis and Is Altered by Maternal Undernutrition. Diabetes, 65(3), 554-560.

https://doi.org/10.2337/db15-0228

28. Miller, S. L., Huppi, P. S., \& Mallard, C. (2016). The consequences of fetal growth restriction on brain structure and neurodevelopmental outcome. The Journal of Physiology, 594(4), 807-823. https://doi.org/10.1113/JP271402

29. Miranda, J., Simões, R. V., Paules, C., Cañueto, D., Pardo-Cea, M. A., García-Martín, M. L., Crovetto, F., Fuertes-Martin, R., Domenech, M., Gómez-Roig, M. D., Eixarch, E., Estruch, R., Hansson, S. R., Amigó, N., Cañellas, N., Crispi, F., \& Gratacós, E. (2018). Metabolic profiling and targeted lipidomics reveals a disturbed lipid profile in mothers and fetuses with intrauterine growth restriction. Scientific Reports, 8(1), 13614. https://doi.org/10.1038/s41598-018-31832-5 
30. Onalan, E., Yakar, B., Barım, A. O., \& Gursu, M. F. (2020). Serum apelin and resistin levels in patients with impaired fasting glucose, impaired glucose tolerance, type 2 diabetes, and metabolic syndrome. Endokrynologia Polska, 71(4), 319-324. https://doi.org/10.5603/EP.a2020.0024

31. Palmer, A. C. (2011). Nutritionally mediated programming of the developing immune system. Advances in Nutrition (Bethesda, Md.), 2(5), 377-395.

https://doi.org/10.3945/an.111.000570

32. Palou, M., Priego, T., Romero, M., Szostaczuk, N., Konieczna, J., Cabrer, C., Remesar, X., Palou, A., \& Pico, C. (2015). Moderate calorie restriction during gestation programs offspring for lower BAT thermogenic capacity driven by thyroid and sympathetic signaling. International Journal of Obesity, 39(2), 339-345.

https://doi.org/10.1038/ijo.2014.56

33. Pervanidou, P., \& Chrousos, G. P. (2011). Stress and Behavior: The Role of Nutrients with Emphasis on Omega-3 Fatty Acids. In A. P. Simopoulos (Ed.), World Review of Nutrition and Dietetics (Vol. 102, pp. 44-52). KARGER.

https://doi.org/10.1159/000327790

34. Peterside, I. E., Selak, M. A., \& Simmons, R. A. (2003). Impaired oxidative phosphorylation in hepatic mitochondria in growth-retarded rats. American Journal of Physiology. Endocrinology and Metabolism, 285(6), E1258-1266. https://doi.org/10.1152/ajpendo.00437.2002

35. Schröder, H. J. (2003). Models of fetal growth restriction. European Journal of Obstetrics, Gynecology, and Reproductive Biology, 110 Suppl 1, S29-39.

https://doi.org/10.1016/s0301-2115(03)00170-2

36. Sharma, D., Farahbakhsh, N., Shastri, S., \& Sharma, P. (2016). Intrauterine growth restriction - part 2. The Journal of Maternal-Fetal \& Neonatal Medicine, 29(24), 40374048. https://doi.org/10.3109/14767058.2016.1154525

37. Silva, J. E. (2006). Thermogenic Mechanisms and Their Hormonal Regulation. Physiological Reviews, 86(2), 435-464. https://doi.org/10.1152/physrev.00009.2005 
38. Syggelos, N., Augoulea, A., Armeni, E., Kaparos, G., Vafaei, H., Dontas, I., Marinou, K., Vaggos, G., Raptou, P., Lambrinoudaki, I., Eleftheriades, M., \& Nicolaides, K. H. (2021). Impact of prenatal and postnatal nutritional manipulation on bone quality in adult Wistar rats offspring. Clinical Nutrition Open Science, 35, 34-47. https://doi.org/10.1016/j.nutos.2020.12.004

39. Thorn, S. R., Regnault, T. R. H., Brown, L. D., Rozance, P. J., Keng, J., Roper, M., Wilkening, R. B., Hay, W. W., \& Friedman, J. E. (2009). Intrauterine growth restriction increases fetal hepatic gluconeogenic capacity and reduces messenger ribonucleic acid translation initiation and nutrient sensing in fetal liver and skeletal muscle. Endocrinology, 150(7), 3021-3030. https://doi.org/10.1210/en.2008-1789

40. Vickers, M. H., Breier, B. H., Cutfield, W. S., Hofman, P. L., \& Gluckman, P. D. (2000). Fetal origins of hyperphagia, obesity, and hypertension and postnatal amplification by hypercaloric nutrition. American Journal of Physiology. Endocrinology and Metabolism, 279(1), E83-87. https://doi.org/10.1152/ajpendo.2000.279.1.E83

41. Wang, D., Hartmann, K., Seweryn, M., \& Sadee, W. (2018). Interactions Between Regulatory Variants in CYP7A1 (Cholesterol 7a-Hydroxylase) Promoter and Enhancer Regions Regulate CYP7A1 Expression. Circulation: Genomic and Precision Medicine, 11(10). https://doi.org/10.1161/CIRCGEN.118.002082

42. Wang, J., Chen, L., Li, D., Yin, Y., Wang, X., Li, P., Dangott, L. J., Hu, W., \& Wu, G. (2008). Intrauterine growth restriction affects the proteomes of the small intestine, liver, and skeletal muscle in newborn pigs. The Journal of Nutrition, 138(1), 60-66.

https://doi.org/10.1093/in/138.1.60

43. Widdowson, E. M. (1971). Intra-uterine growth retardation in the pig. I. Organ size and cellular development at birth and after growth to maturity. Biology of the Neonate, 19(4), 329-340. https://doi.org/10.1159/000240427

44. Williams, G. R., \& Bassett, J. H. D. (2011). Local control of thyroid hormone action: Role of type 2 deiodinase. Journal of Endocrinology, 209(3), 261-272.

https://doi.org/10.1530/JOE-10-0448 
45. Wu, G., Bazer, F. W., Wallace, J. M., \& Spencer, T. E. (2006). Board-invited review: Intrauterine growth retardation: implications for the animal sciences. Journal of Animal Science, 84(9), 2316-2337. https://doi.org/10.2527/jas.2006-156

46. Wu, Guoyao, Imhoff-Kunsch, B., \& Girard, A. W. (2012). Biological mechanisms for nutritional regulation of maternal health and fetal development. Paediatric and Perinatal Epidemiology, 26 Suppl 1, 4-26. https://doi.org/10.1111/j.1365-3016.2012.01291.x 47. Young, M. F., \& Ramakrishnan, U. (2021). Maternal Undernutrition before and during Pregnancy and Offspring Health and Development. Annals of Nutrition and Metabolism, 1-13. https://doi.org/10.1159/000510595

48. Zhu, W.-F., Tang, S.-J., Shen, Z., Wang, Y.-M., \& Liang, L. (2017). Growth hormone reverses dyslipidemia in adult offspring after maternal undernutrition. Scientific Reports, 7(1), 6038. https://doi.org/10.1038/s41598-017-05045-1

49. Zinkhan, E. K., Yu, B., \& McKnight, R. (2019). Uteroplacental Insufficiency Impairs Cholesterol Elimination in Adult Female Growth-Restricted Rat Offspring Fed a High-Fat Diet. Reproductive Sciences (Thousand Oaks, Calif.), 26(9), 1173-1180. https://doi.org/10.1177/1933719118811649

50. Zouridis, A., Manousopoulou, A., Potiris, A., Sarli, P.-M., Aravantinos, L., Pervanidou, P., Deligeoroglou, E., Garbis, S. D., \& Eleftheriades, M. (2021). Impact of Maternal Food Restriction on Heart Proteome in Appropriately Grown and Growth-Restricted Wistar-Rat Offspring. Nutrients, 13(2), 466. https://doi.org/10.3390/nu13020466 51. Young, M. F., \& Ramakrishnan, U. (2021). Maternal Undernutrition before and during Pregnancy and Offspring Health and Development. Annals of Nutrition and Metabolism, 1-13. https://doi.org/10.1159/000510595

52. Aravidou, E., Eleftheriades, M., Malamitsi-Puchner, A., Anagnostopoulos, A. K., Aravantinos, L., Dontas, I., Aravidis, C., Creatsas, G., Tsangaris, G., \& Chrousos, G. P. (2015). Protein expression in the brain of rat offspring in relation to prenatal caloric restriction. The Journal of Maternal-Fetal \& Neonatal Medicine, 1-8.

https://doi.org/10.3109/14767058.2015.1102222 